\title{
Enhanced Bandwidth of Band Pass Filter Using a Defected Microstrip Structure for Wideband Applications
}

\author{
Sanae Azizi ${ }^{1}$, Mustapha El Halaoui ${ }^{2}$, Abdelmoumen Kaabal ${ }^{3}$, Saida Ahyoud ${ }^{4}$, Adel Asselman $^{5}$ \\ 1,2,3,5 Department of Physics, Optic and Photonic Team, Faculty of Science, Abdelmalek Essaadi University, Morocco \\ ${ }^{4}$ Department of Physics, Information Technology and Systems Modeling Team, Faculty of Science, \\ Abdelmalek Essaadi University, Morocco
}

\begin{tabular}{l} 
Article Info \\
\hline Article history: \\
Received Jan 9, 2018 \\
Revised Jul 2, 2018 \\
Accepted Jul 29, 2018 \\
\hline Keyword: \\
Bandpass filter \\
Bandwidth enhancement \\
DMS \\
Ring-shaped \\
Wideband applications
\end{tabular}

Article Info

Aricle history:

Received Jan 9, 2018

Revised Jul 2, 2018

(2.

\begin{abstract}
In this paper, the bandwidth enhancement of bandpass filter (BPF) is proposed by utilizing defected microstrip structure (DMS). The initial micro strip BPF which is designed to have the bandwidth $1 \mathrm{GHz}$ with the center frequency of $3.5 \mathrm{GHz}$ is deployed on FR4 Epoxy dielectric substrate with overall size and thickness of $14 \mathrm{~mm} \times 24 \mathrm{~mm}$ and $1.6 \mathrm{~mm}$, respectively. The proposed filter consists of two parallel coupled lines centred by ring-shaped, to enhance the bandwidth response, an attempt is carried out by applying DMS on the ligne center with a ring-shaped of initial filter. Here, the proposed DMS is constructed of the arrowhead dumbbell. Some parametrical studies to the DMS such as changing to obtain the optimum geometry of DMS with the desired bandwidth response. From the characterization result, it shows that the utilization of DMS on to the microstrip ligne of filter has widened $3 \mathrm{~dB}$ bandwidth response up to $1.8 \mathrm{GHz}$ ranges from $2.55 \mathrm{GHz}$ to $4.35 \mathrm{GHz}$ yielding an enhanced wideband response for various wideband wireless applications.
\end{abstract}

Copyright ( 92018 Institute of Advanced Engineering and Science. All rights reserved.

\section{Corresponding Author:}

Sanae Azizi,

Departement of Physics, Optics and Photonics Team,

Abdelmalek Essaadi University,

Faculty of Science, P.O. Box 2121, Tetouan, Morocco.

Email: sanae.azizi5@gmail.com

\section{INTRODUCTION}

The development of wireless communication technology has been remarkably increasing during the last decade. Basically the development is addressed to fulfill the demand for high speed communications $[1,2]$. Numerous investigation efforts have also been conducted to satisfy the demand by upgrading existing technologies applied in some devices with the new ones. However, the improvement sometimes arises some obstacles regarding the limited capability of related devices including amplifier, power combiner/splitter, and filter [3, 4].

Bandpass filters are prime components in communication systems as they help to inhibit interference and provide the needed selection of the signal band. Bandpass filters that possess high selectivity in the passband are needed to suit modern communication applications. [5].

Printed microstrip filter is widely used due to their numerous advantages such as low profile, low cost, easy fabrication, and small size. Major operational disadvantage of microstrip filter is very narrow frequency bandwidth. In some applications narrow bandwidths are desirable [6]-[9]. By consequent, the needs of wideband bandpass filter have been proposed and investigated of new technologies to overcome these shortcomings. 
Several different techniques have been proposed and reported in literature to increase the bandwidth of microstrip such as Defected Ground Structure [10]-[13], asymmetric couple-line filter with annular ring EBG structure [14], Stub-Loaded Resonator [15], PIN diode [16], uniplanar compact PBG (UC-PBG) [17],quadruple-mode stub-loaded resonator [18] and multi-short-stub multi-mode resonator [19].

Defected Microstrip Structure (DMS) is one of the methods, which are used to improve the bandwidth of the microstrip filter and very useful in microwave because the disturbance occurs at the microstrip line. DMS is realized by inserted a simple shape in the microstrip ligne. The implementation of DMS in the microstrip surface can increase the bandwidth of the original microstrip filter. Also DMS is more easily integrated with other microwave circuits and has an effectively reduced circuit size, compared with DGS. Finally the DMS does not change the geometry of the ground plane and helps to avoid leakage of radio frequency signals [20]-[21].

The main objective of this work is to enhance the performance of a bandpass filter in terms of better return loss and increased bandwidth the bandpass filter resonating at $3.5 \mathrm{GHz}$ by employing DMS element in microstrip filter. The proposed DMS is placed on the ligne center of initial filter which is deployed on FR4 Epoxy dielectric substrate is designed to have working bandwidth wider than $1 \mathrm{GHz}$ as the improvement effect from the original bandwidth response.

The article is organized as follows. Section 2 presents a brief description of the initial band pass filter. Section 3 is devoted to the DMS concept that is introduced in the initial filter and we will see its effect on the s-parameters. Comparison of the results between the bandpass filter without DMS and with DMS are shown in section 4. Finally, section 5 is devoted to conclusion.

\section{MICROSTRIP BAND PASS FILTER}

The proposed filter is given in Figure 1 (a). It is a band pass filter based on the structure of a parallel coupled microstrip line. Among the advantages of this element include compact size, simple structure, and wide stopband. The proposed design consists of two parallel coupled lines with a ring-shaped. The designed filter has two identical parallel lines with an electrical length of about a quarter wavelength at the desired center frequency. The third line is centred between the two extreme lines with different lengths and widths. The width of the middle line is W3, and W2 is the width of the two other extreme lines. The lengths of the middle line at the left- and right-hand sides are L3 and L2, respectively. The above elements are spaced by gap spacing $\mathrm{S}$.

As illustrated in Figure 1, the geometry and configuration of the proposed filter is designed and optimized using CST Microwave Studio software simulator on FR4 substrate of dielectric constant $=4.4$, substrates thickness $\mathrm{h}=1.6 \mathrm{~mm}$, copper thickness $\mathrm{t}=35 \mu \mathrm{m}$, and tangent loss $\tan \delta=0.025$, the characteristic impedance of the microstrip line was taken as $50 \Omega$.

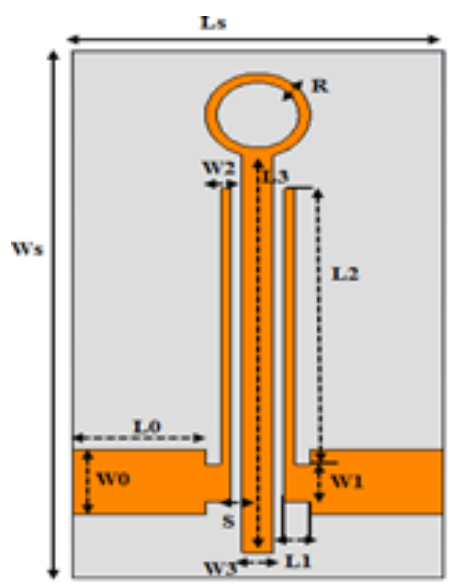

(a)

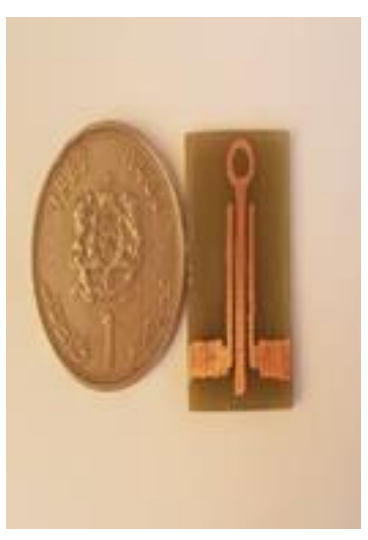

(b)

Figure 1. (a) Geometry of the proposed bandpass filter (b)Photograph of the fabricated bandpass filter

The designed bandpass filter structure is manufactured and tested in the laboratory, and the practical results are well compatible with those simulated. The measurements of the diffusion parameters of the 
proposed filter were made by a Rohde and Schwarz ZVB vector network analyzer 20, whose frequency range is limited to $20 \mathrm{GHz}$. A photograph of the manufactured filter is shown in Figure 1 (b). The outer dimension of the prototype was $14 \mathrm{~mm} \times 25 \mathrm{~mm}$. The related dimensions of the BPF as indicated in Figure 1. They are in $\mathrm{mm} \mathrm{Ls}=14, \mathrm{~L} 0=5, \mathrm{~L} 1=1, \mathrm{~L} 2=13.2, \mathrm{~L} 3=19, \mathrm{~L} 4=2.45, \mathrm{WS}=24, \mathrm{~W} 0=3, \mathrm{~W} 1=1.9$, W2=0.4, W3=1.9, $\mathrm{S}=0.4$ and $\mathrm{R}=0.44$.

Figure 2 shows the results of the variation of the S-parameters as a function of the frequencies simulated and measured as well as those of the group delay of the proposed filter. There is a reasonable agreement between the results of the simulation and those measured, although there shift in the resonate frequency justified by manufacturing errors. The resonance frequency is centered at $3.5 \mathrm{GHz}$, with a return loss, S11, better than $-20 \mathrm{~dB}$ and insertion loss, S21, around $-0.1 \mathrm{~dB}$ have been obtained particularly in the passband from 3.1 to $4.1 \mathrm{GHz}$ and the $3-\mathrm{dB}$ fractional bandwidth of the filter is found to be $27.77 \%$. The group delay varies from 0.30 to $0.45 \mathrm{~ns}$. In other words, the maximum variation in group delay achieves 0.45 ns, indicating a good linearity phase linearity and better performance in time domain.

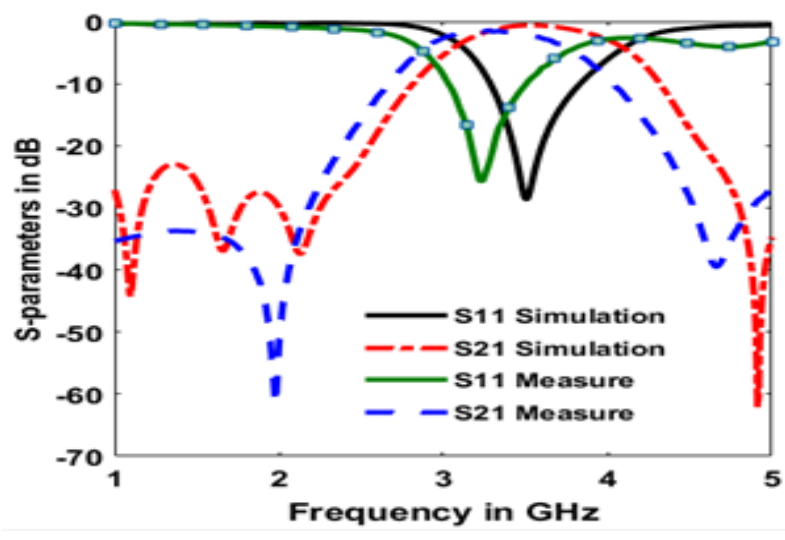

(a)

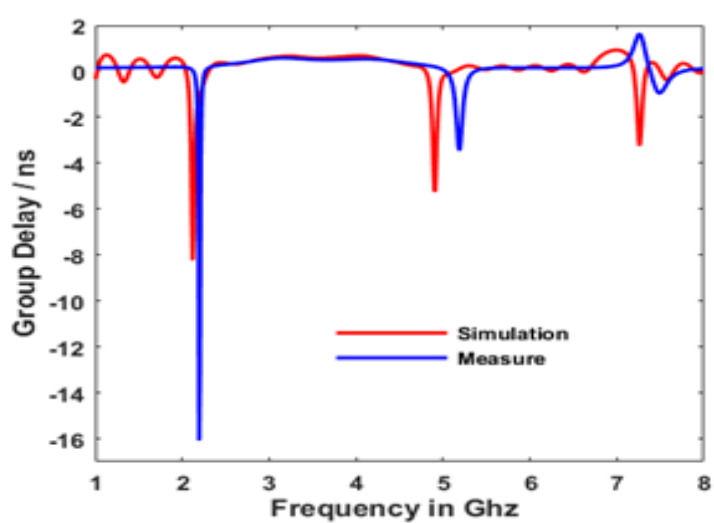

(b)

Figure 2. Comparison of simulated and experimental results for the bandpass filter (a) simulated S parameter, (b) Group Delay

\section{BAND PASS FILTER WITH DMS}

To improve the bandwidth of the proposed filter we introducing defected microstrip structure (DMS). Figure 3 illustrates the utilization of the arrowhead-slot of DMS over the microstrip ligne.it show that the proposed DMS is placed on the ligne center with a ring-shaped of initial filter.
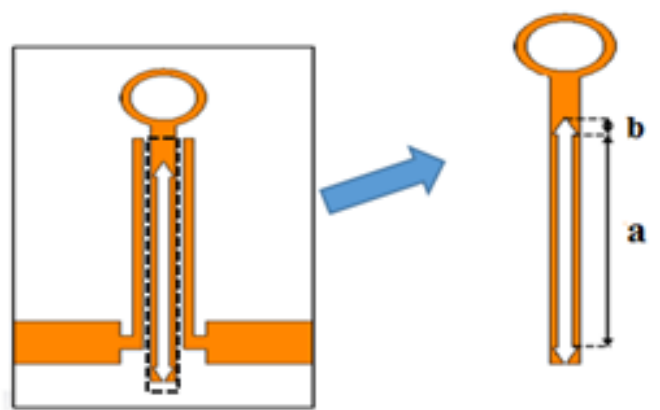

Figure.3. Geometry of the band pass filter with DMS

\subsection{Parametric Study}

The performance of the filter is affected by these geometric parameters. To optimize the filter and to have more information on the effects of the design parameters a parametric study of the DMS structure is carried out. Simulated S-parameter performance with variation in parameter (a) is depicted in Figure 4. Better 
return-loss and insertion loss characteristics have been observed for a=13.2 mm. For higher value of (a), insertion-loss in the passband is increased. Also, decrease in $-10 \mathrm{~dB}$ return-loss bandwidth is observed for lower value of a. In the stopband, slight variation in insertion-loss is found with good return-loss performance.

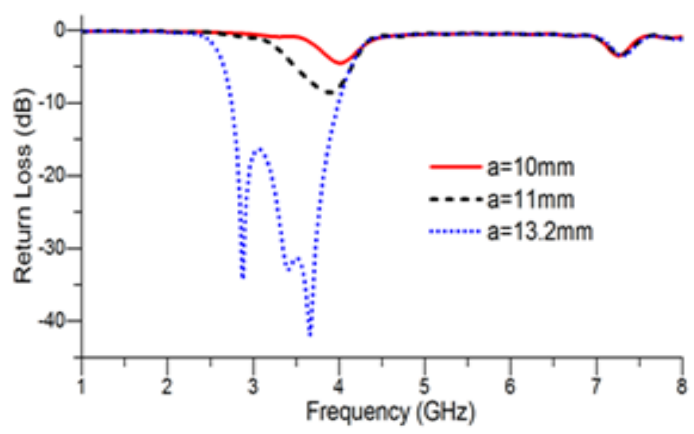

(a)

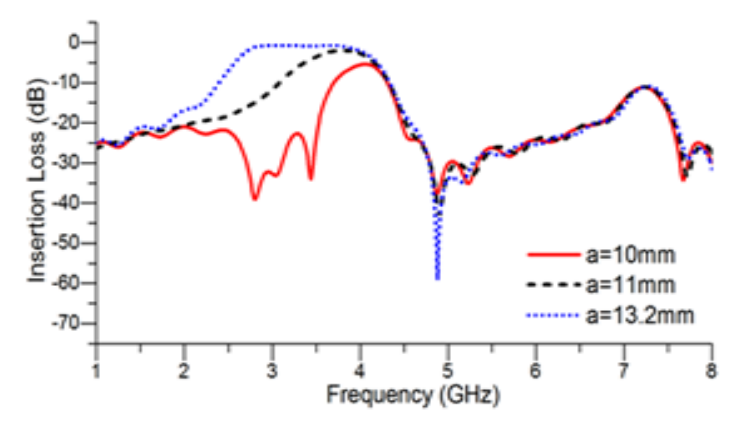

(b)

Figure 4. The effect of a (length of the arrowhead-slot) on the proposed filter response. (a) Effect on return loss $|\mathrm{S} 11|$. (b) Effect on insertion loss $|\mathrm{S} 21|$

The effect of variation of parameter (b) on S-parameter characteristics is plotted in Figure. 5. From Figure 5, it is seen that insertion-loss and return-loss performance are better for $(b)=1.1 \mathrm{~mm}$. When (b) increases from $0.5 \mathrm{~mm}$ to $1.1 \mathrm{~mm}$, the return losses become more matched and centred at the desired frequency of $3.5 \mathrm{GHz}$, from the graphs, we can clearly see that the insertion-loss increases when (b) is increased.

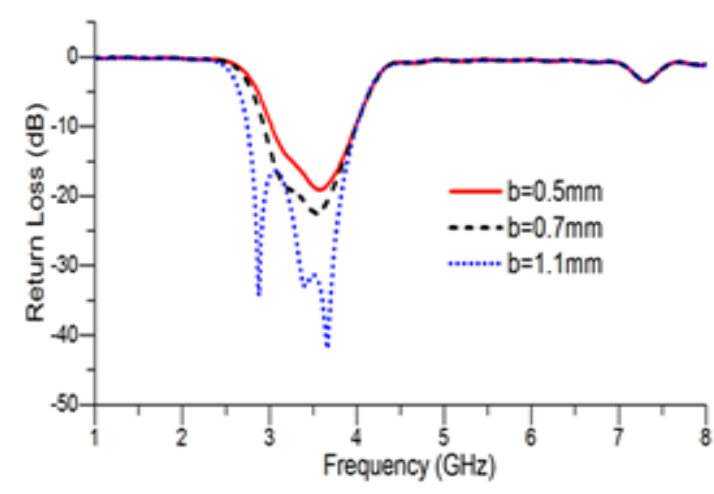

(a)

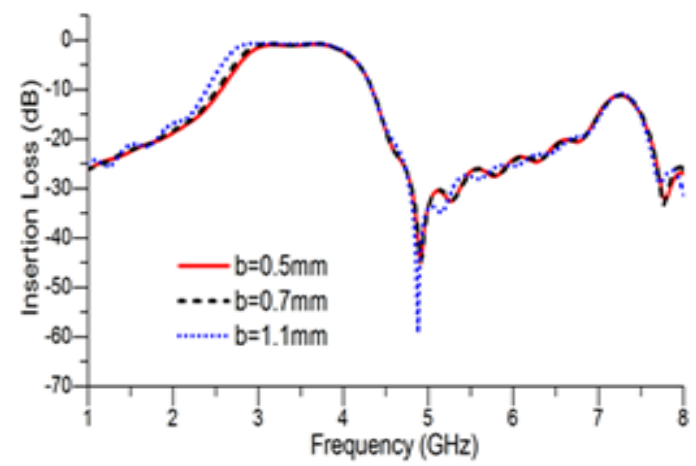

(b)

Figure 5. The effect of $b$ (length of the arrowhead-slot) on the proposed filter response. (a) Effect on return loss $|\mathrm{S} 11|$. (b) Effect on insertion loss $|\mathrm{S} 21|$

The related dimensions of the final BPF with DMS as shown in Figure 3 are determined as follows (all in $\mathrm{mm}$ ), $\mathrm{Ls}=14, \mathrm{~L} 0=5, \mathrm{~L} 1=1, \mathrm{~L} 2=13.2, \mathrm{~L} 3=19, \mathrm{~L} 4=2.45, \mathrm{WS}=24, \mathrm{~W} 0=3, \mathrm{~W} 1=0.9, \mathrm{~W} 2=0.4, \mathrm{~W} 3=1.9$, $\mathrm{S}=0.4$ and $\mathrm{R}=0.44, \mathrm{a}=13.2, \mathrm{~b}=1.1$. (With a size of $14 \times 24 \mathrm{~mm}^{2}$ ).

Next we present our filter band pass with DMS fabrication and compare simulation with measurement results.

\subsection{Measurement Results and Discussion}

Arrowhead-slot DMS presents a greater slow wave effect, since it has more discontinuities, providing a longer trajectory to the electromagnetic wave. To validate the performance, a prototype of proposed BPF with DMS is fabricated based on optimized dimensional parameters and measured. The

Enhanced Bandwidth of Band pass Filter Using a Defected Microstrip Structure for... (Sanae Azizi) 
photograph of top fabricated prototype is represented in Figure 6. To validate the simulation results the performance parameters of BPF with DMS are measured and compared with simulated results.

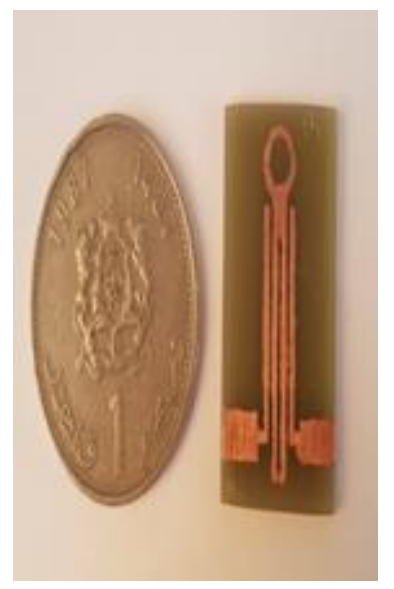

Figure 6. Photograph of the fabricated wide bandpass filter with DMS

The comparison between simulated and measured return-loss and insertion-loss performance is plotted in Figure 7 (a), and they are found to be in good agreement with each other. It can be seen that the measured insertion-loss, $|\mathrm{S} 21|$ is better than $0.6 \mathrm{~dB}$ within the entire $-10 \mathrm{~dB}$ return loss passband from 2.55 $\mathrm{GHz}$ to $4.35 \mathrm{GHz}$ irrespective of simulated $|\mathrm{S} 21|$ which is better than $0.4 \mathrm{~dB}$ whereas return-loss is more than $20 \mathrm{~dB}$.

The measured return-loss in upper-stopband is almost flat and agrees with simulated response and performance better than $0.4 \mathrm{~dB}$ extended up from 4.8 to $8 \mathrm{GHz}$. Also the measured and simulated insertionloss in this frequency band of interest is found to be better than $15 \mathrm{~dB}$. So the proposed pass band filter with DMS has well out of band rejection performance with very wide upper- stopband characteristic.

The group delay performance for proposed bandpass filter with DMS is plotted in Figure 7(b) showing a good agreement between simulated and measured result. It is observed that the group delay varies between 0.2 to $0.35 \mathrm{~ns}$ within the desired UWB frequency band. The little discrepancy in simulated and measured results may be due to fabrication tolerances and improper soldering of SMA connector.

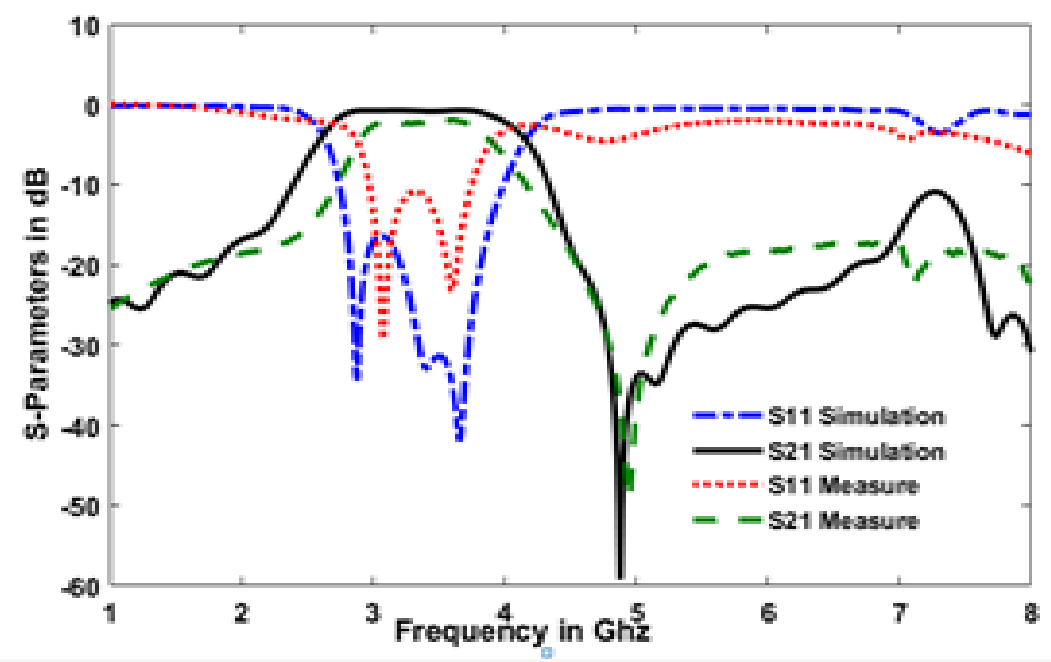

(a) 


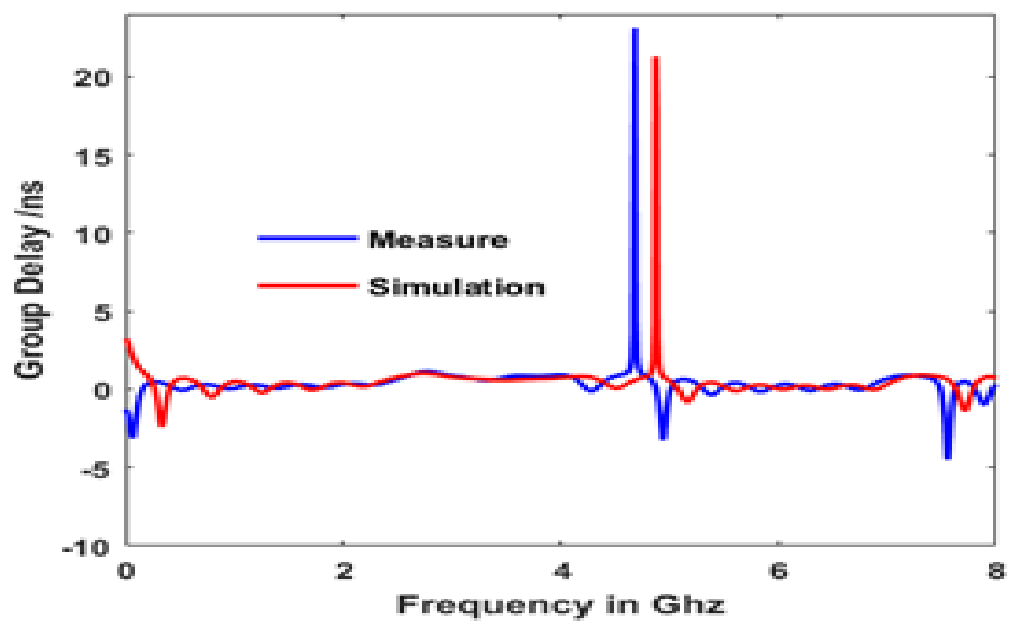

(b)

Figure 7. Comparison of simulated and experimental results for the bandpass filter with DMS (a) simulated $S$-parameter, (b) Group Delay

\section{COMPARISON CONVENTIONAL BAND PASS FILTER AND BAND PASS FILTER WITH DMS}

To show the bandwidth enhancement of initial UWB microstrip BPF, the simulation Technology Microwave Studio (CST MWS) is used to characterize the effect of DMS incorporation into the microstrip ligne. Figure 8 plots the characterization result of proposed UWB microstrip BPF with DMS in comparison with the initial filter design .It seems that the proposed BPF has the bandwidth response better than others, whilst the initial microstrip BPF and other types of BPF provide results which are not suitable with the desired criteria.Hence, by incorporating DMS into the microstrip ligne, the passband bandwidth response of UWB microstrip BPF could be enhanced with the bandwidth achievement up to $1.8 \mathrm{GHz}$ ranges from the frequency of $2.55 \mathrm{GHz}$ to $4.35 \mathrm{GHz}$. Table 1 shows the comparison the performance of the intial filter and the filter with DMS.

Table 1. Performance Comparison of the Bandpass Filter without DMS and Bandpass Filter with Arrowhead-

\begin{tabular}{ccc} 
& slot DMS \\
\hline Filter parameter & BPF without DMS & BPF with DMS \\
\hline Fc $(\mathrm{GHz})$ & 3.5 & 3.45 \\
Return loss $(\mathrm{dB})$ & 0.1 & 0.4 \\
Insertion loss $(\mathrm{dB})$ & $>-20$ & $>-30$ \\
Band pass $(\mathrm{GHz})$ & $3.1-4.1$ & $2.55-4.35$ \\
FBW\% & 27.77 & 52.17 \\
\hline
\end{tabular}

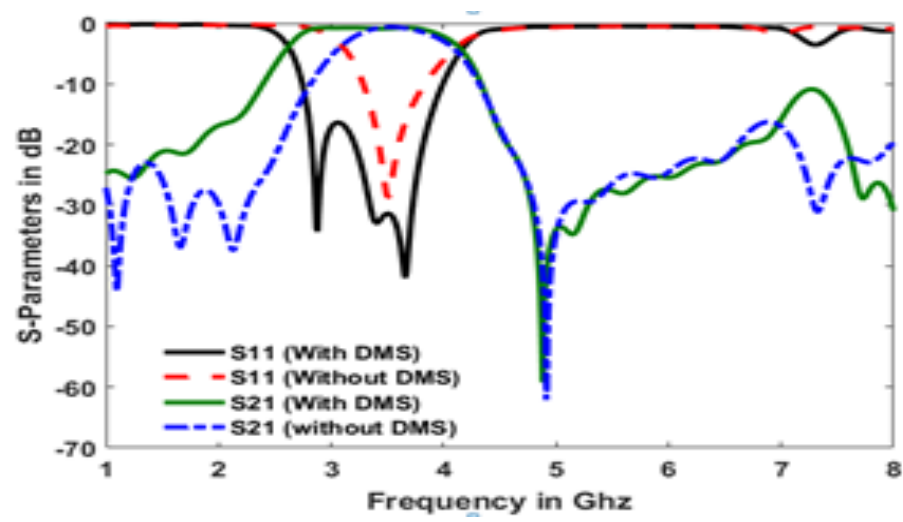

Figure 8. The comparison between the band pass filter without and with DMS 
To further demonstrate the performance of the filter, Table 2 is provided for comparison of this work with others works which are all based on wide-band bandpass filter category. As illustrated in this table the poroposed method DMS had the best performance in terms of bandwith in comparaison with several techniques proposed in literature, $24.4 \%$ reponse up for our technique and $9.42 \%$ and $5.6 \%$ for annular ring EBG structure and Defecet Ground Structure respectively.

Table 2. Comparison with Some Reported Similar Bandpass Filters

\begin{tabular}{|c|c|c|c|c|c|}
\hline \multirow{2}{*}{ Ref } & \multirow{2}{*}{$\begin{array}{c}\boldsymbol{f}_{\boldsymbol{c}} \\
(\mathrm{GHz})\end{array}$} & \multicolumn{2}{|c|}{ FBW (\% ),BW(MHz) } & \multirow{2}{*}{ BW Enhancement } & \multirow{2}{*}{ Types of Resonator } \\
\hline & & Without technique & With technique & & \\
\hline Our proposed & 3.5 & $27.77 \%$ & $52.17 \%$ & $24.4 \%$ & Defecet Microstrip Structure \\
\hline [19] & 15.86 & $18.9 \%$ & $36 \%$ & $17.4 \%$ & $\begin{array}{l}\text { Multi-Short-Stub Multi-mode } \\
\text { resonator }\end{array}$ \\
\hline [18] & 2 & $22 \%$ & $34 \%$ & $12 \%$ & $\begin{array}{l}\text { quadruple-mode stub-loaded } \\
\text { resonator }\end{array}$ \\
\hline [16] & 1.5 & $29 \%$ & $50 \%$ & $21 \%$ & PIN diode \\
\hline [14] & - & $39.39 \%$ & $48.81 \%$ & $9.42 \%$ & Annular ring EBG structure \\
\hline [13] & 2.4 & $171 \mathrm{MHz}$ & $180 \mathrm{MHz}$ & $5.6 \%$ & Defecet Ground Structure \\
\hline
\end{tabular}

\section{CONCLUSION}

The bandwidth enhancement of microstrip BPF has been investigated by utilizing arrowhead -slot structure DMS in ligne center with ring-shaped. The parametric analysis of different variable of the structure DMS was carried out to obtain the optimized dimensions. Hence, from the comparison of characterization results between the initial filter and the proposed filter with DMS, it has been demonstrated that the utilization of DMS has successfully enhanced the bandwidth response up to $24.4 \%$ from the initial. However, the proposed filter with DMS has shown an improved and acceptable performance which can be applied to various WIMAX and wideband wireless applications.

\section{ACKNOWLEDGEMENTS}

The authors would like to express their deepest gratitude to Naima A. Touhami from Electronics Instrumentation and microwave Laboratory, Faculty of Sciences. Abedlmalek Essaadi University, for the measurement and the technical support

\section{REFERENCES}

[1] H. Perros, "High-Speed Communication Networks," 1992.

[2] J. Wang, "High-Speed Wireless Communications: Ultra-wideband, 3G Long Term Evolution, and 4G Mobile System," 2008.

[3] J. Vancl, V. Sokol, P. Cerny, and Z. Skvor, "The UWB Amplifier 3.1-10.6 GHz," in Microwave Techniques, 2008. COMITE 2008. 14th Conference on, 2008, pp. 1-4.

[4] A. Munir, T. Praludi, and M. R. Effendi, "Characterization of narrowband hairpin bandpass filter composed of fractal Koch geometry," in 35th Progress In Electromagnetics Research Symposium (PIERS) Proc, 2014, pp. $1843-1846$.

[5] A. N. Obadiah, M. R. Hamid, M. K. A. Rahim, and N. A. Murad, "A Compact Bandpass Filter Using A T-Shaped Loaded Open-ended Stub Resonator," Indonesian Journal of Electrical Engineering and Computer Science, (IJEECS) vol. 10, no. 3, pp. 867-874, 2018.

[6] R. E. Arif, M. Aziz Muslim, and S. H. Pramono, "Compact Stepped Impedance Resonator Bandpass Filter with Tunable Transmission Zeros," TELKOMNIKA (Telecommunication Computing Electronics and Control, vol. 15, no. 4, p. 1689, Dec. 2017.

[7] H. Chen, P. Tang, K. Chen, H. Zhao, and H. Zhong, "Wideband dual-mode bandpass filter using a modified righttriangular patch resonator overlapped with input/output DMS," J. Electromagn. Waves Appl., vol. 27, no. 11, pp. 1365-1371, Jul. 2013.

[8] J.-M. Huang, B. Zhang, and S. S. Li, "Novel compact quad-mode wideband bandpass filter with wide stopband using T-shaped resonator," J. Electromagn. Waves Appl., vol. 28, no. 3, pp. 326-333, Feb. 2014.

[9] T. Ge, Y. Jinping, and W. U. Wen, "Design of Bandpass Filters Using Three Parallel Coupled-Lines with Open Stub Resonator,”电子学报, vol. 22, no. CJE-1, pp. 192-194, 2013.

[10] W. Aditomo and A. Munir, "Bandwidth enhancement of ultra-wideband microstrip bandpass filter using defected ground structure," in Proceedings of 13th International Conference on Quality in Research (QiR), Yogyakarta, Indonesia, Jun. 2013, pp. 150-154.

[11] S. Elajoumi, A. Tajmouati, A. Errkik, A. Sanchez, and M. Latrach, "Microstrip Rectangular Monopole Antennas with Defected Ground for UWB Applications," International Journal of Electronics and Communication Engineering (IJECE), vol. 7, no. 4, p. 2027, Aug. 2017. 
[12] Shita Fitria Nurjihan and Achmad Munir, "Effect of DGS Incorporation for Bandwidth Enhancement of UWB Microstrip BPF," The 3rd International Conference on Wireless and Telematics 2017, Palembang, Indonesia, 27Jul-2017

[13] D. Fitsum, D. Mali, and M. Ismail, "Bandwidth Enhancement of Rectangular Microstrip Patch Antenna using Defected Ground Structure,” Indonesian Journal of Electrical Engineering and Computer Science., vol. 3, no. 2, p. 428, Aug. 2016

[14] S. Parvez, N. Sakib, and N. Mollah, "The $1 \times 1$ annular ring: Bandwidth enhancement of microstrip asymmetric couple-line bandpass filter with superior matching and lower insertion loss," in Electrical Information and Communication Technology (EICT), 2015 2nd International Conference on, 2015, pp. 368-372.

[15] Yalin Ma, Wenquan Che, Jianxin Chen, and Wenjie Feng, "High Selectivity Balanced Bandpass Filter with Tunable Bandwidth Using Stub-Loaded Resonator," Progress In Electromagnetics Research Letters, Vol. 55, , 2015, pp. 89-95, 2015.

[16] W.-H. Tu, "Compact Low-Loss Reconfigurable Bandpass Filter with Switchable Bandwidth," IEEE Microw. Wirel. Components Lett. vol. 20, no. 4, pp. 208-210, Apr. 2010

[17] C. Fang, F. Xu, and L. Yang, "A UWB bandpass filter using interdigital and periodic UC-PBG structures," in Wireless Symposium (IWS), 2016 IEEE MTT-S International, 2016, pp. 1-3.

[18] Xiaoguo Huang, Quanyuan Feng, and Qianyin Xiang, "Bandpass Filter With Tunable Bandwidth Using QuadrupleMode Stub-Loaded Resonator," IEEE Microwave.Wireles. Components Lett, vol. 22, no. 4, pp. 176-178, Apr. 2012.

[19] M. Shen, X. Q. Lin, and Z. He, “A wideband bandpass filter with multi-mode resonator and mixed electromagnetic coupling," International Journal of Microwave and Wireless Technologies., vol. 9, no. 08, pp. 1653-1659, Oct. 2017.

[20] C. Gupta, M. Kumar, and R. S. Meena, "Design and Analysis of Triple Notched Band Uwb Band Pass Filter Using Defected Microstrip Structure (Dms)," International Journal of Wireless Communications and Mobile Computing"., vol. 5, no. 6, p. 32, 2018

[21] M. A. Mutalib, Z. Zakaria, W. Y. Sam, and A. A. M. Isa, "Simulation and Analysis of Compact Defected Microstrip Structure (DMS) with Narrow Bandwidth Notch Characteristics," Journal of Telecommunication, Electronic and Computer Engineering. Jtec, vol. 6, no. 2, pp. 1-4, 2014. 